\title{
Developing a Customer-Oriented Model for Medical Tourism Alliance Management of Taiwanese Hospitals
}

\author{
Cheng-Ru Wu, Hui-Yin Tsai, Chia-Chun Liao, and Chiu-Chin Chen
}

\begin{abstract}
This study attempts to select the best medical tourism alliance model by examining the perspectives of hospital customers in Taiwan. Adopted herein is the renowned BOCR model, which influences how competitive advantages especially with respect to developing and evaluating the objectives of optimal medical tourism alliance selection are related in order to devise a standardized operational procedure. In addition to a literature review and interviews with experts, this study adopts the modified Delphi method, analytic hierarchy process (AHP), and grey relational analysis (GRA) in order to develop an evaluation method for selecting the optimal medical tourism alliance in Taiwan to determine its effectiveness. Finally, we found that the expert is preferred over the Medical Holding Company. The proposed evaluation criterion provides a valuable reference for determining the optimal alliance structure for Taiwan's emerging medical tourism sector and provides high-level management of hospital institutions, government supervisors, and academicians with recommendations for future development.
\end{abstract}

Index Terms-Medical tourism, analytical hierarchy process, grey relational analysis.

\section{INTRODUCTION}

In countries around the world, hospitals and the tourism industry have cooperated for several decades. Indeed, medical tourism originated in the seventeenth century. Bies and Zacharia [1] believe that medical tourism is a medical outsourcing service that performs expensive operations at a lower cost.

Currently, medical industry advancements, the original purpose of international tourism, travel, transformed into a search for genuine health care services, such as health clinics, beauty treatments, surgery, etc. [2], [3]. In Taiwan, medical tourism industry and its related academia has been vigorously discussed and implemented in recent years.

Taiwan has taken on a leading position in the world of high-quality health care in recent years. Taiwan medical services emphasis refinement, humanity, and low cost advantages, so Taiwan has an opportunity for the

Manuscript received October 8, 2013; revised January 6, 2014.

C. R. Wu is with the Department of Leisure Recreation \& Travel Management, Toko University, No.51, Sec. 2, Syuefu Rd., Puzih City, Chiayi County 61363, Taiwan, R.O.C. (e-mail: alexru01@gmail.com).

H. Y. Tsai is with the Department of Hospitality Management, Toko university, No.51, Sec. 2, Syuefu Rd., Puzih City, Chiayi County 61363, Taiwan, R.O.C. (e-mail: remipipi2005@gmail.com).

C. C. Liao is with the Department of Information Technology and Management, Tzu Chi college of Technology, 880, Sec2, Chien-Kuo Road, Hualien, 97005 Taiwan, R.O.C. (e-mail: jonathan.liao.mis@gmail.com).

C. C. Chen is with the Institute of Information Management, National Chiao Tung University, 1001 University Road, Hsin Chu 30010, Taiwan, R.O.C. (e-mail: jennifer.chen.mis@gmail.com). development of international medical tourism [4].

The literature applies the BOCR model to examine the most suitable models of medical tourism alliances is limited. Only William and Zacharia [1] have assumed four evaluation criteria based on the BOCR model to explore the most suitable structure for alliances in the case of medical outsourcing, and have discussed the best alternatives of medical tourism based on customers, selections. Therefore, this study extends the subject and presents an evaluation method based on the BOCR model and from the hospital customer-oriented in order to identify developmental trends and factors that will give enterprises a competitive advantage in the medical tourism alliance industry.

This study defined four criteria and fifteen sub-criteria for use in evaluating four alternative models of medical tourism alliance. The main criteria and sub-criteria were introduced at the suggestion of experts, and other factors were based on existing literature. Following a literature review and interviews with experts in the field, the Modified Delphi Method was adopted in order to reach a consensus among anonymous experts.

As a decision support system, we used the analytic hierarchy process (AHP) [5], [6] and grey relational analysis (GRA) [7]-[9]. Based on those results, an attempt was made to understand alliance application and competition mode strategies in the medical tourism industry. The results of this study provide a valuable reference for governments and industries in promoting the growth potential of this emerging sector.

\section{LITERATURE REVIEW}

\section{A. Brief Summary}

The form of medical tourism alliance varies considerably around the world depending on local jurisdictional regulations and market characteristics.

In this paper, medical tourism alliance structures are classified into four categories basis of the hospitals whether cross-operation tourism business activities by the aforementioned studies and the current status and business model of medical tourism alliance in Taiwan. We introduce the following alliance structures:

\section{1) Precompetitive alliance}

'Precompetitive alliance' means that two or more companies from different industries unite in order to achieve a particular goal. It can combine different producers in the same marketing channels or sell the goods of the same producer through different marketing channels. 'Precompetitive alliance' also means that the agreement or the cooperative relationship is usually established according to the terms of a 
written contract.

Moreover, it has a specified duration and does not establish a new company. For the purposes of this study, medical tourism is a good example, which includes entities such as the tourism industry, airlines, insurance, hotels, and the leisure industry.

\section{2) Collaboration partnership}

When no equity is involved it yields a more flexible partnership between the two sides and may extend cooperation within the desired time frame. This kind of partnership often appears in the supplier relationship.

Within medical tourism, patients in foreign countries are referred to Taiwanese hospitals through local hospitals (the upstream of the hospital). The two hospitals do not have equity or operational forms of involvement, just like mutual cooperation in industry partnerships.

\section{3) Health management company}

'Health management company' implies the role of a medical provider. A hospital set up by an internal Health management company is responsible for external marketing, advertising, investments, and business but also for customers and the hospital's channel of communication.

\section{4) Medical holding company}

A Medical holding company is a medical conglomerate that engages in at least two different industries as a single entity, including all kinds of medical, tourism, and insurance industries. For the purposes of this study, Medical holding companies include hospitals, travel agencies, hotels, shopping centers, and all kinds of leisure facilities. In brief, Medical holding company integrates various industries and allows companies listing requirements for the international medical establishment.

\section{EVAlUATION MODEL AND CASE IMPLEMENTATION}

In this paper, the criteria for the evaluation decision model are derived by following an exhaustive literature review through use of the modified Delphi method.

After constructing the evaluation criteria hierarchy, we calculate the criteria weights by applying the AHP [10]. Finally, we conduct the GRA [11] to achieve the final ranking results.

\section{A. Analytic Hierarchy Process}

When deals the complex issue, we can be performed decompose the hierarchy structure. Based on the human cannot comparison above the seven kind things at the same time, so we must assume each elements of the hierarchy that do not suitably surpass seven elements.

Under this limited condition, it may carry on the reasonable comparison and easier ensure the consistency [10]. The first hierarchy of the structure that is we want to achieve goal. Under the end hierarchy is the choice projects or replacement alternatives, as well as the each middle hierarchies are the appraisal factor or criteria.

\section{1) Various hierarchies' elements weight computation}

\section{a) Establishment of pair-wise comparison matrix $A$}

Based on an element of the upper hierarchy is an evaluating standard, going on the pair-wise comparison to each elements. If has the $n$ elements must make $n(n-1) / 2$ elements of the pair-wise comparison. Let $C_{1}, C_{2}, \ldots, C_{n}$ denote the set of elements, while $a_{i j}$ represents a quantified judgment on a pair of elements $C_{i}, C_{j}$.

The relative importance of two elements is rated using a scale with the values $1,3,5,7$, and 9 , where 1 refers to "equally important", 3 denotes "slightly more important", 5 equals "strongly more important", 7 represents "demonstrably more important" and 9 denotes "absolutely more important". This yields an $n$-by- $n$ matrix $A$ as follows:

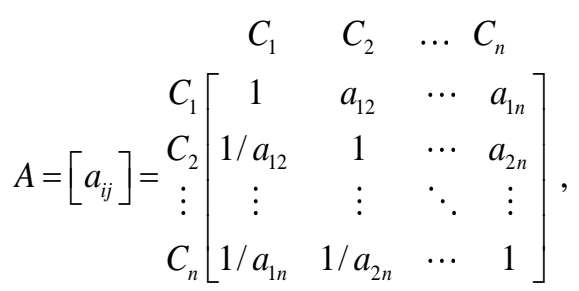

where $a_{i j}=1$ and $a_{i j}=1 / a_{i j}, i, j=1,2, \ldots, n$. In matrix $A$, the problem becomes one of assigning to the $\mathrm{n}$ elements $C_{1}, C_{2}, \ldots, C_{n}$ a set of numerical weights $W_{1}, W_{2}, \ldots$, $W_{n}$ that reflects the recorded judgments. If $A$ is a consistency matrix, the relations between weights $W_{i}$ and judgments $a_{i j}$ are simply given by $W_{i} / W_{j}=a_{i j}$ (for $i, j=1,2, \ldots, n$. ) and matrix $A$ as follows:

$$
A=\begin{array}{cccc}
C_{1} & C_{2} & \cdots & C_{n} \\
C_{1} \\
C_{2} \\
C_{n}
\end{array}\left[\begin{array}{cccc}
w_{1} / w_{1} & w_{1} / w_{2} & \cdots & w_{1} / w_{n} \\
w_{2} / w_{1} & w_{2} / w_{2} & \cdots & w_{2} / w_{n} \\
\vdots & \vdots & \ddots & \vdots \\
w_{n} / w_{1} & w_{n} / w_{2} & \cdots & w_{n} / w_{n}
\end{array}\right],
$$

b) Calculating the eigenvalue and eigenvector

Matrix $A$ multiply the elements weight vector $(x)$ equal to $n x$, that is $(A-n I) x=0$, the $x$ is the Eigenvalue $(n)$ of Eigenvector. Due to $a_{i j}$ be makers' subjective judgment give comparison and appraisal, with the truly value $\left(W_{i} / W_{j}\right)$ have the same level degree difference, so that $A x=n . x$ can not to be set up. Saaty [12] suggested that the largest eigenvalue $\lambda_{\max }$ be:

$$
\lambda_{\max }=\sum_{j=1}^{n} a_{i j} \frac{W_{j}}{W_{i}}
$$

If $A$ is a consistency matrix, eigenvector $X$ can be calculated by

$$
\left(A-\lambda_{\max } I\right) X=0
$$

c) Performing the consistency test

The essential idea of the AHP is that a matrix $A$ of rank $n$ is only consistent if it has one positive eigenvalue $n=\lambda_{\max }$ while all other eigenvalues are zero. Further, Saaty developed the consistency index $(C I)$ to measure the deviation from a consistent matrix:

$$
C I=\left(\lambda_{\max }-n\right) /(n-1),
$$


The consistency ratio $(C R)$ is introduced to aid the decision on revising the matrix or not. It is defined as the ratio of the $C I$ to the so-called random index $(R I)$ which is a $C I$ of randomly generated matrices:

$$
C R=C I / R I
$$

For $n=3$ the required consistency ratio $\left(C R^{\text {Goal }}\right)$ should be less than 0.05 , for $n=4$ it should be less than 0.08 and for $n \geq$ 5 it should be less than 0.1 to get a sufficient consistent matrix Otherwise the matrix should be revised [13].

In brief, $R I$ represents the average consistency index over numerous random entries of same order reciprocal matrices. If $C R \leq 0.1$, the estimate is accepted: otherwise, a new comparison matrix is solicited until $C R \leq 0.1$.

This study defined four criteria and fifteen sub-criteria for use in evaluating four alternative models of medical tourism alliance. The main criteria and sub-criteria were introduced at the suggestion of experts, and other factors were based on existing literature.

Following a literature review and interviews with experts in the field, the Modified Delphi Method was adopted in order to reach a consensus among anonymous experts.

\section{B. Grey Relational Analysis}

Deng developed the Grey system method, which has been extensively applied in various fields [11], including decision science. In this study, the GRA is applied to construct an evaluation method for selecting the preferable energy collaboration management model.

Let $X_{0}$ be the referential series with $k$ entities (or criteria) of $X_{1}, X_{2}, \ldots, X_{i}, \ldots, X_{N}$ (or $N$ measurement criteria). Then

$$
\begin{gathered}
X_{0}=\left\{x_{0}(1), x_{0}(2), \ldots, x_{0}(j), \ldots, x_{0}(k)\right\} \\
X_{1}=\left\{x_{1}(1), x_{1}(2), \ldots, x_{1}(j), \ldots, x_{1}(k)\right\} \\
\vdots \\
X_{i}=\left\{x_{i}(1), x_{i}(2), \ldots, x_{i}(j), \ldots, x_{i}(k)\right\} \\
\vdots \\
X_{N}=\left\{x_{N}(1), x_{N}(2), \ldots, x_{N}(j), \ldots, x_{N}(k)\right\},
\end{gathered}
$$

The grey relational coefficient between the compared series $X_{i}$ and the referential series of $X_{0}$ at the $j$-th entity is defined as

$$
\gamma_{0 i}(j)=\frac{\Delta \min +\Delta \max }{\Delta_{0 i}(j)+\Delta \max },
$$

where $\Delta_{0 i}(j)$ denotes the absolute value of difference between $X_{0}$ and $X_{i}$ at the $j$-th entity, that is $\Delta_{0 i}(j)=\left|x_{0}(j)-x_{i}(j)\right|$, and $\Delta \max =\max _{i} \max _{j} \Delta_{0 i}(j), \Delta \min =\min _{i} \min _{j} \Delta_{0 j}(j) \cdot$

The grey relational grade (GRG) for a series of $X_{i}$ can be expressed as

$$
\Gamma_{0 i}=\sum_{j=1}^{K} w_{j} \gamma_{0 i}(j)
$$

where $w_{j}$ represents the AHP weight of $j$-th entity.

Before calculating the grey relation coefficients, the data series can be treated based on the following three kinds of situations and the linearity of data normalization to avoid distorting the normalized data. They are:

1) Upper-bound effectiveness measuring (i.e., largerthe-better)

$$
x_{i}^{*}(j)=\frac{x_{i}(j)-\min _{j} x_{i}(j)}{\max _{j} x_{i}(j)-\min _{j} x_{i}(j)}
$$

where $\max _{j} x_{i}(j)$ is the maximum value of entity $j$ and $\min _{j} x_{j}(j)$ is the minimum value of entity $j$.

2) Lower-bound effectiveness measuring (i.e., smallerthe-better)

$$
x_{i}^{*}(j)=\frac{\max _{j} x_{i}(j)-x_{i}(j)}{\max _{j} x_{i}(j)-\min _{j} x_{i}(j)}
$$

Data normalized for sixteen sub-criteria using equation (9) and (10), than computing with $\Delta_{0 i}(j)$.

\section{Final Customer-Oriented Models Score}

Since the sub-criteria weights have been obtained from AHP and GRA, the GRG weights can be calculated by equations (8). Table I summarizes those results. Summaries of the optimal medical tourism alliance in Taiwan: Precompetitive Alliances (0550), Collaboration Partnership (0.542), Health Management Company (0.718) and Medical Holding Company (0.983). Medical Holding Company performs the best.

TABLE I: SUMMARIES OF THE GRG $\Gamma_{0 i}$

\begin{tabular}{lll}
\hline \hline & $\Gamma_{0 i}$ & Rank \\
\hline $\begin{array}{l}\text { Precompetitive } \\
\text { Alliances }\end{array}$ & 0550 & 3 \\
$\begin{array}{l}\text { Collaboration } \\
\begin{array}{l}\text { Partnership } \\
\text { Health Management }\end{array}\end{array}$ & 0.542 & 4 \\
$\begin{array}{l}\text { Company } \\
\text { Medical Holding } \\
\text { Company }\end{array}$ & 0.718 & 2 \\
\hline \hline
\end{tabular}

\section{CONCLUSIONS AND FUTURE WORK}

AHP is widely used in multi-criteria decision-making problems. One of the main advantages of this method is that it can effectively manage tangible and intangible or qualitative and quantitative factors. This study attempts to use the customer-oriented model to find the most preferred alliance structure of medical tourism alliances, which is a problem that involves complex multi-criteria decision-making.

In this paper, AHP is included in most operations research and management science, and it is used extensively in organizations that have carefully investigated its theoretical underpinnings. One of the features of the GRA is that both qualitative and quantitative relationships can be identified among complex factors with insufficient information.

Using the GRA to analysis the four alternative models of 
medical tourism alliance in Taiwan. The summarize are Precompetitive Alliances (0550), Collaboration Partnership (0.542), Health Management Company (0.718) and Medical Holding Company (0.983).

This result even more clearly that the operators of hospital cooperate with each other whether synergies generated for the executive is very important. And through consultation with the operators, government authorities, and academicians, we learned that the present Taiwan's medical tourism alliance models comprise the Precompetitive Alliances, Collaboration Partnership, Health Management Company and Medical Holding Company. Summarizing the results, the Medical Holding Company received higher overall value scores largely because it had higher scores.

This study provides an evaluation criterion for determining the optimal alliance structure for Taiwan's emerging medical tourism sector, and the proposal evaluation criterion provides high-level management of medical institutions and academicians with recommendations for future development.

\section{ACKNOWLEDGMENT}

This research is supported by the "National Science Council" of Taiwan under the grant No. NSC 102-2410-H-464-002-MY2.

\section{REFERENCES}

[1] B. William and L. Zacharia, "Medical tourism: outsourcing surgery," Mathematical and Computer Modeling, vol. 46, no. 7-8, pp. 1144-1159, October 2007.

[2] J. Connell, "Medical tourism: sea, sun, sand and ...surgery," Tourism Management, vol. 27, no. 6, pp. 1093-1100, December 2006.

[3] A. Smyth, "Multiresistant pulmonary infection in cystic fibrosis-prevention is better than cure," The Lancet, vol. 366, no. 9484, pp. 433-435, August 2005.

[4] C. R. Wu, C. W. Chang, and H. L. Lin, "FAHP sensitivity analysis for measurement nonprofit organizational performance," Quality \& Quantity, vol. 42, no. 3, pp. 283-302, June 2008.

[5] C. R. Wu, C. W. Chang, and C. C. Liao, "Selection of collaborative technology used by software contractors," Journal of Testing and Evaluation, vol. 38, no. 6, pp. 731-737, November 2010.

[6] C. W. Chang, C. R. Wu, and C. C. Chen, "Determining the performance of collaborative design systems based on AHP sensitivity analysis," Journal of Testing and Evaluation, vol. 38, no. 6, pp. 759-766, November 2010.

[7] D. S. Chang and C. C. Liao, "Identifying the key factors for chiller system collaborative service design," Energy and Buildings, vol. 49, pp. 286-293, June 2012.

[8] C. R. Wu, C. W. Chang, and C. C. Chen, "Applying expert diagnosis model to collaborative design systems, " Advanced Science Letters, vol. 4, no. 4-5, pp. 1860-1861, April-May 2011.

[9] C. C. Chen and A. P. Chen, "Constructing a test method to evaluate collaborative cloud finance information system," International
Journal of Innovation, Management and Technology, vol. 4, no. 1, pp. 141-143, February 2013.

[10] T. L. Saaty, The Analytic Hierarchy Process, New York: McGraw-Hill, 1980.

[11] J. L. Deng. "Introduction to grey system," Journal of Grey System, vol. 1, no. 1, pp. 1-24, 1989

[12] T. L. Saaty, "How to make a decision: the analytic hierarchy process," European Journal of Operational Research, vol. 48, no. 1, pp. 9-26, 1990.

[13] T. L. Saaty, The Fundamentals of Decision Making and Priority Theory with the Analytic Hierarchy Process, AHP Series, Pittsburgh: RWS Publication, pp. 1-527, 1994.

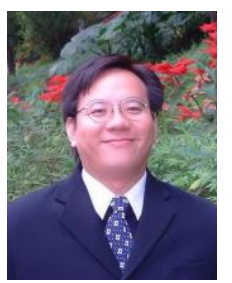

Cheng-Ru Wu is a professor of Department of Leisure Recreation \& Travel Management, Toko University. He holds Ph.D. in the management from Ming Chuan University.

His major interests are in the area of real options, management science quantitative methods, social science research methods, performance evaluation and financial engineering.

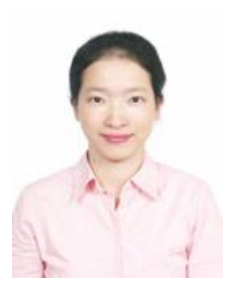

Hui-Yin Tsai is an associate professor of Department of Hospitality Management, Toko University. She holds Ph.D. in the management from Ming Chuan University.

Her major interests are in the area of general management, research methods and marketing management.

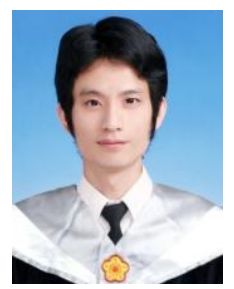

Chia-Chun Liao is an assistant professor of Department of Information Technology and Management, Tzu Chi college of Technology. He holds $\mathrm{Ph} . \mathrm{D}$. in the management from National Central University, Taoyuan, Taiwan.

He has published over 20 journal and conference papers. Currently, His major interests are in the area of semiconductor quality engineering, software quality engineering, system evaluation, cloud computing, technology management, service science, grey system, optimization theory and applications.

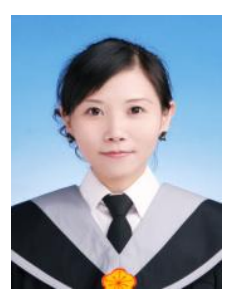

Chiu-Chin Chen received a B.S. degree from Yuanpei University, Taiwan, in 2007, and an M.S. degree from Yuanpei University, Taiwan, in 2010, all in information management. She is currently working toward the Ph.D. degree with the Institute of Information Management, National Chiao Tung University, Hsinchu, Taiwan.

She has published over 20 journal and conference papers. Currently, she is the Ph.D candidate with the Institute of Information Management, National Chiao Tung University, Hsinchu, Taiwan. Her recent research interests are in cloud computing, collaborative technology, financial management, and e-learning system. 